\title{
Moderating effects of information-oriented versus escapism-oriented motivations on the relationship between psychological well-being and problematic use of video game live-streaming services
}

\author{
CHI-YING $\mathrm{CHEN}^{1} *$ and SHAO-LIANG CHANG ${ }^{2}$ \\ ${ }^{1}$ Department of Information Communication, Asia University, Taichung, Taiwan \\ ${ }^{2}$ Business Administration, Asia University, Taichung, Taiwan
}

(Received: November 23, 2018; revised manuscript received: March 7, 2019; second revised manuscript received: May 17, 2019; third revised manuscript received: May 29, 2019; accepted: June 9, 2019)

\begin{abstract}
Background and aims: Video game live-streaming platforms are widely used by gamers. However, the excessive use of such services has rarely been examined. Although psychosocial well-being and motivations for use have been demonstrated to play major roles in online addiction, understanding the moderating mechanism of these two factors is warranted. Video game live-streaming platforms are an ideal context for studying the moderating role of both informational and escapism motivations, because viewers on such platforms can learn gaming strategies or escape from the reality. Methods: This study collected survey data from 508 users of the highly popular gamestreaming service Twitch. The sample was divided into two groups based on the respondents' use motivations. Regression models with interaction terms were fitted, followed by a simple slope test, to verify the hypotheses. Results: For the escapism-oriented group, a moderating effect of escapism on the relationship between loneliness and negative outcomes was found; the relationship was positive for low and moderate levels of escapism, but it was non-significant for individuals with high levels of escapism. For the information-oriented group, information seeking was observed to exert a moderating effect on the relationship between stress and negative outcomes; the relationship was negative for low and moderate levels of information seeking, but it was non-significant for individuals demonstrating high levels of information seeking. Discussion and conclusions: The findings promote understanding regarding how individuals using similar Internet-related coping strategies to deal with problems differ in their propensity for experiencing negative consequences when motivation levels and online environments are considered.
\end{abstract}

Keywords: video game live streaming, online game addiction, Internet addiction, motivations, moderating effects

\section{INTRODUCTION}

Internet addiction (also termed excessive Internet use or problematic Internet use) has been described as a disorder wherein an individual uses the Internet excessively despite experiencing negative outcomes (Young, 1998), and an extensive body of literature has been written on this topic since the late 1990s (Kardefelt-Winther, 2014a). Because of the wide variety of activities that occur online, the umbrella term "Internet addiction" has been criticized for lacking specificity (Baggio et al., 2018; Kuss, Griffiths, \& Pontes, 2017).

Addiction to online gaming was included separately in the fifth edition of Diagnostic and Statistical Manual of Mental Disorders as a tentative disorder (American Psychiatric Association, 2013). Furthermore, the World Health Organization (WHO) included Gaming Disorder (GD) in the International Classification of Diseases (ICD-11) released in 2018 (WHO, 2018). The decision to include GD in the ICD-11 has initiated much debate. Researchers noted that non-problematic gaming might be stigmatized by the inclusion of GD in the ICD-11 and that gaming is better conceptualized as a coping mechanism instead of as a disorder (van Rooij et al., 2018). However, a group of researchers supported the WHO perspective, recognizing clinical and public health needs on the grounds of clinical evidence (Rumpf et al., 2018). In the context of these wider debates, problematic use of online games has become a popular research subject in its own right. However, video game live-streaming platforms, which are becomingly increasingly popular, have rarely been examined. On such platforms, streamers broadcast real-time video and audio content from the games they are playing. Viewers on a streamer's channel can comment on their performance or simply interact with other viewers and the host via instant

\footnotetext{
* Corresponding author: Assoc. Prof. Chi-Ying Chen, Department of Information Communication, Asia University, No. 500 Lioufeng Rd., Wufeng, Taichung 41354, Taiwan; Phone: +886 0973 830 711; E-mail: megcychen@asia.edu.tw
}

This is an open-access article distributed under the terms of the Creative Commons Attribution-NonCommercial 4.0 International License, which permits unrestricted use, distribution, and reproduction in any medium for non-commercial purposes, provided the original author and source are credited, a link to the CC License is provided, and changes - if any - are indicated. 
chat. According to recent data, more than 100 million unique users use Twitch monthly, making it the world's leading streaming and social platform for gamers. Approximately half of Twitch's users spend more than $20 \mathrm{hr}$ a week watching live streams on the platform (Smith, 2018). A new hub, FB.gg, introduced by Facebook is also attempting to capitalize on the growing audience for gaming live streams (Fortune, 2018). Despite their popularity, the literature still lacks comprehensive works examining the use of such video game live-streaming services.

Most research on excessive Internet use or online gaming has employed a biomodel framework of addiction and compulsive behaviors (Petry et al., 2014). For example, many studies have revealed an association between problematic Internet use and emotion dysregulation (Hollett \& Harris, 2019) or various psychosocial difficulties, such as low self-esteem (Chen, 2018; Ehrenberg, Juckes, White, \& Walsh, 2008; Fioravanti, Dettore, \& Casale, 2012), loneliness (Bozoglan, Demirer, \& Sahin, 2013; Guo, You, Gu, $\mathrm{Wu}$, \& Xu, 2018; Kim, LaRose, \& Peng, 2009), stress, depression, and anxiety (Ostovar et al., 2016; Pontes \& Griffiths, 2016). In addition, research using motive-oriented approaches has noted escapism as a key predictor of Internet or online game addiction (Király et al., 2015; Kuss, Louws, \& Wiers, 2012; Laconi, Pirès, \& Chabrol, 2017; Parker \& Plank, 2000; Yee, 2007; Zanetta et al., 2011). Information seeking is another major motivation for going online. This motivation, also known as "instrumental use," was demonstrated to be unrelated to negative outcomes, in contrast to "ritual use" (i.e., use motivated by escapism), which is a crucial factor in Internet addiction (Song, Larose, Eastin, \& Lin, 2004). Similar results were reported in a study of compulsive YouTube use (Klobas, McGill, Moghavvemi, \& Paramanathan, 2018). By contrast, Bae's research (2017) indicated that both information seeking and escapism are associated with heavy smartphone dependence. In a study on the excessive use of general video-streaming services, information seeking was associated with negative outcomes (Hasan, Jha, \& Liu, 2018).

Research employing a biomodel framework of addiction and compulsive behaviors has focused on direct effects (i.e., main effects) models of psychosocial or motivational factors on problematic Internet use. However, some people may experience negative outcomes from going online, whereas others may experience positive outcomes (Hinkley, Timperio, Salmon, \& Hesketh, 2017; Kuo, Lutz, \& Hiler, 2016; McNicol \& Thorsteinsson, 2017). An alternative perspective of compensatory Internet use may offer useful insights. This view asserts that excessive Internet use is more properly conceptualized and investigated as a compensatory or coping strategy rather than as a compulsion (Kardefelt-Winther, 2014a, 2014b, 2017) because Internet use can constitute a coping behavior to alleviate dysfunctional moods or distract attention from real-life problems (Hasan et al., 2018; Kardefelt-Winther, 2014b; Kuss et al., 2012; Shen \& Williams, 2011; Young, 2009). Therefore, the effects of psychosocial factors may be moderated by such coping behaviors. In other words, individuals with maladaptive coping behavior may be more likely to experience negative outcomes. Proponents of the compensatory Internet use perspective argue that analytical focus should transcend direct effects models and move toward an interaction effects model, exploring how motivations moderate the relationship between psychosocial well-being and problematic Internet use (Kardefelt-Winther, 2014a, 2017).

As mentioned above, escapism is often indicated to be the best motivational predictor for Internet addiction. This construct is also highly controversial in gaming-related literature. Hagström and Kaldo (2014) elucidated positive escapism versus negative escapism. In the same vein, Kuo et al. (2016) distinguished active escapism from passive escapism; active escapism refers to physical enactment or mental participation through the involvement of fantasy, whereas passive escapism refers to psychological immersion to escape a troublesome reality. Their study indicated an association between active escapism and positive outcomes of affirmation and empowerment. Deleuze et al. (2019) engaged in a similar discourse by arguing that escapism can represent experiential avoidance that is involved in a wide range of psychological problems and is often associated with problematic usage patterns. By contrast, escapism could arise from a positive or adaptive use of online environments to manage stress and relax. Many studies have indicated interaction effects from the negative potential of escapism and other vulnerability factors, such as psychiatric distress, psychosocial well-being, or lack of coping resources (Ballabio et al., 2017; Bowditch, Chapman, \& Naweed, 2018; Cheng, Sun, \& Mak, 2015; Demetrovics et al., 2011; Király et al., 2015; McNicol \& Thorsteinsson, 2017). In addition, some studies have concluded that escapism motivations partially mediate the relationship between psychosocial difficulties and problematic gaming (Blasi et al., 2019; Maroney, Williams, Thomas, Skues, \& Moulding, 2018).

Game playing and the viewing of game streaming differ in essence, although both activities are gaming related. Game playing can function as a physically or mentally enacted activity that overturns the divisions between the body and machine by extending the body into a virtual space and allowing for new identities (Chen, 2013; Lahti, 2003). This process could potentially represent a positive aspect of game-playing escapism that might not be applicable to live game-streaming viewing. However, the viewing of streaming games can function as a learning paradigm. Taking Twitch as a research target, Payne, Keith, Schuetzler, and Giboney (2017) concluded that worked-example styles of learning (i.e., learning from a streamer's demo) and learning from novices' mistakes in live-streaming environments improved participants' performance. Thus, information seeking and learning are the major feature for game-streaming viewing but might not be common for game playing. Therefore, the role of information seeking has rarely been examined in gamerelated studies, although extensive research has tested its effect on a variety of Internet uses (Bae, 2017; Hasan et al., 2018; Klobas et al., 2018). Game-streaming platforms are an ideal context for studying the influences of both information-oriented and escape-oriented use, because viewers on such platforms can learn skills and strategies for their favorite games as well as escape from real-life or emotional problems merely by watching gaming. 
Based on compensation theory, the aim of this study was to explore the moderating effects of both informationoriented and escapism-oriented motivations on the relationship between psychosocial well-being and problematic use of live game-streaming. Two indicators of psychosocial well-being, namely loneliness and stress, were selected from other studies on excessive Internet use. Loneliness was suggested as a major psychosocial factor driving individuals' Internet use for relief, and this process could easily develop into a problematic usage pattern resulting in negative outcomes (Bozoglan et al., 2013; Kim et al., 2009). In addition, loneliness was found to partially mediate the association between quality of social relationships and Internet addiction (Guo et al., 2018). In one study that established a valid and reliable instrument for assessing the psychometric properties of GD, stress was indicated as the best psychometric predictor (Pontes \& Griffiths, 2016). In general, both loneliness and stress have been suggested as psychosocial risk factors for problematic Internet use (Ostovar et al., 2016).

After a thorough review of the literature, the following hypotheses were proposed:

H1: Escapism moderates the relationship between loneliness and negative outcomes, and this relationship is positive when levels of escapism are high.

$H 2$ : Escapism moderates the relationship between stress and negative outcomes, and this relationship is positive when levels of escapism are high.

H3: The relationship between loneliness and negative outcomes is not moderated by information seeking.

H4: The relationship between stress and negative outcomes is not moderated by information seeking.

\section{METHODS}

\section{Recruitment and sample}

To reach the targeted subjects (i.e., users of video game livestreaming services), information regarding this study and a link to an online survey were posted on Twitch and its Facebook page. Participants completing the survey were offered, by lottery, an incentive in the form of a Cheer, a sold chat message that comprises evolving animated emotes used to support streamers on Twitch. A total of 508 participants completed the questionnaire. Of these 508 participants, $58.8 \%$ were male and $41.7 \%$ were female, and their ages ranged from 16 to 47 years [mean $(M)=20.42$, standard deviation $(S D)=3.85]$.

\section{Measurement}

The measurement was adapted from well-established constructs in the literature to ensure item reliability and validity. The online questionnaire contained questions assessing demographic variables regarding gender, age, psychosocial well-being, motivations, and negative outcomes caused by using of video game live-streaming services. Five-point Likert scales were used throughout $(1=$ strongly disagree and $5=$ strongly agree); a higher score was considered to indicate a higher strength for the factor.
Psychosocial factors. Loneliness and stress were assessed using a selection of items borrowed from validated questionnaires. An abridged three-item loneliness scale was used to measure loneliness (Pittman \& Reich, 2016). A fouritem short form of the Perceived Stress Scale was used to measure stress (Warttig, Forshaw, South, \& White, 2013). The Cronbach's $\alpha$ for this study was acceptable at .75 for loneliness and .70 for stress.

Motivations. Escapism was evaluated with three items from the escapism scale of Yee (2007) that were adapted to game-streaming watching (Appendix). Information seeking as a motivation was evaluated with four items from other studies on Internet addiction (Song et al., 2004) and binge-watching behavior (Sung, Kang, \& Lee, 2018) adapted to game-streaming viewing (Appendix). Exploratory factor analysis ensured that the items for each variable were loaded on the same factor (all factor loadings $>0.70$ ). The Cronbach's $\alpha$ was good at .76 for escapism and .78 for information seeking.

Negative outcomes. Negative outcomes were assessed with five items adapted from a study on online gaming (Kardefelt-Winther, 2014a). Exploratory factor analysis confirmed that all five items were loaded on the same factor (all factor loadings $>0.80$ ). The Cronbach's $\alpha$ of .92 was excellent.

\section{Statistical analyses}

Data were analyzed using SPSS (version 22.0, developed by IBM in Chicago, IL, USA), and the variables employed for analysis were derived by calculating the average number of items for each measurement. In order to identify motivation orientation, k-means cluster analysis was performed with a priori fixed number of two clusters based on the motivation variables: escapism and information seeking. A cluster analysis splits data into clusters so that objects of the same group are more similar to each other than those in other groups, and k-means is a widely used clustering technique (Codeahoy, 2017). Regression models with interaction terms were fitted to verify the research hypotheses. Predicted regression coefficients for negative outcomes from independent variables of psychosocial factors (loneliness and stress) and motivations (escapism and information seeking) were used to plot the significance of any interaction effects. To reduce multicollinearity, the independent variables were standardized using a centering method (Forest, 2017; Howell, 2012). If a significant interaction effect between psychological well-being and motivation was indicated, a simple slope test was conducted to verify how the different levels of motivation moderated or changed the relationship between the psychological factor and negative outcomes. Simple slope testing was conducted using free software, Interaction (Soper, n.d.), which requires less time and effort for interaction analysis than SPSS does and enables easy creation of interaction graphs.

\section{Ethics}

The study procedures were conducted in accordance with the Declaration of Helsinki. Before participating in the study, all participants were informed of the purpose of the 
study and subsequently provided consent. This study did not involve human or animal experimentation.

\section{RESULTS}

\section{Descriptive statistics and $k$-means cluster analysis}

The normality assumption was justified by the measurement of all skewness and kurtosis between 1 and -1 , as shown in Table 1, which presents the descriptive statistics, distributions, and correlation coefficients.

A k-means analysis was run in order to identify two clusters differing with regard to escapism and informationseeking motives (Table 2). Cluster 1 consisted of 233 participants that were characterized by higher levels of escapism; this group was labeled the "escape-oriented group" (EOG) and used to analyze $H 1$ and $H 2$ regarding the moderating effects of psychosocial factors and escapism motivations. Cluster 2 contained 275 participants that were characterized by higher levels of information seeking; this group was labeled the "information-oriented group" (IOG) and used to analyze $H 3$ and $H 4$ to test the moderating effects of psychosocial factors and information-seeking motivations.

To test the interaction effects between psychosocial wellbeing and escapism, a multiple regression model with negative outcomes as the dependent variable was fitted using the EOG (Table 3). This model explained $29.7 \%$ of the variance for the negative outcomes $\left[F_{(7,225)}\right)=13.57$, $p<.001]$. In support of $H 1$, the data revealed a significant interaction effect between loneliness and escapism $(b=-0.31, t=-2.87, p<.01)$. However, no interaction

Table 1. Descriptive statistics and correlation coefficients between variables

\begin{tabular}{lccccc}
\hline & 1 & 2 & 3 & 4 & 5 \\
\hline 1. Negative outcome & \multicolumn{1}{c}{1} & & & & \\
2. Loneliness & $.09^{*}$ & \multicolumn{1}{c}{1} & & & \\
3. Stress & -.03 & $-.20^{* *}$ & 1 & & \\
4. Escapism & $.12^{* *}$ & $-.52^{* *}$ & $.18^{* *}$ & 1 & \\
5. Information seeking & $.14^{* *}$ & $.18^{* *}$ & $.11^{*}$ & $-.22^{* *}$ & 1 \\
Mean & 2.46 & 3.26 & 2.75 & 2.75 & 2.94 \\
Standard deviation & 0.96 & 0.73 & 0.61 & 0.73 & 0.82 \\
Skewness & 0.02 & 0.44 & -0.17 & 0.04 & -0.16 \\
Kurtosis & -0.86 & -0.02 & 0.39 & 0.38 & -0.49 \\
\hline
\end{tabular}

Note. ${ }^{*} p<.05 .{ }^{* *} p<.01$.

Table 2. Result of k-means cluster analysis

\begin{tabular}{lccccc}
\hline & \multicolumn{2}{c}{$\begin{array}{c}\text { Escape-oriented } \\
\text { group }\end{array}$} & & \multicolumn{2}{c}{$\begin{array}{c}\text { Information-oriented } \\
\text { group }\end{array}$} \\
\cline { 2 - 3 } \cline { 5 - 6 } & \multicolumn{2}{c}{ Cluster 1 $(n=233)$} & & \multicolumn{2}{c}{ Cluster 2 $(n=275)$} \\
\cline { 2 - 3 } \cline { 5 - 6 } & $M$ & $S D$ & & $M$ & $S D$ \\
\hline Escapism & 3.13 & 0.63 & & 2.41 & 0.65 \\
Information & 2.25 & 0.53 & & 3.53 & 0.50 \\
seeking & & & & & \\
\hline
\end{tabular}

Note. $M$ : mean; $S D$ : standard deviation.
Table 3. Multiple regression model for negative outcomes with interaction terms for EOG

\begin{tabular}{lcc}
\hline & $B$ & $t$ \\
\hline Gender & -0.02 & -0.19 \\
Age & 0.00 & -0.11 \\
Loneliness & 0.33 & $3.33^{* *}$ \\
Stress & 0.33 & $3.06^{* *}$ \\
Escapism & 0.81 & $8.87^{* * *}$ \\
Loneliness $\times$ Escapism & -0.31 & $-2.87^{* *}$ \\
Stress $\times$ Escapism & -0.24 & -1.65 \\
$R^{2}$ & .297 & \\
\hline
\end{tabular}

Note. EOG: escape-oriented group.

$* * p<.01 . * * * p<.001$.

effect between stress and escapism was found; therefore, $H 2$ was rejected.

A simple slope test was performed to investigate how escapism moderated the relationship between loneliness and negative outcomes (Figure 1). Table 4 shows that the relationship between loneliness and negative outcomes was positive when levels of escapism were low $(b=0.40$, $t=3.47, \quad p<.001)$ and medium $(b=0.19, \quad t=2.34$, $p<.01)$ but non-significant when levels of escapism were high. This result contradicted $H 1$, indicating that

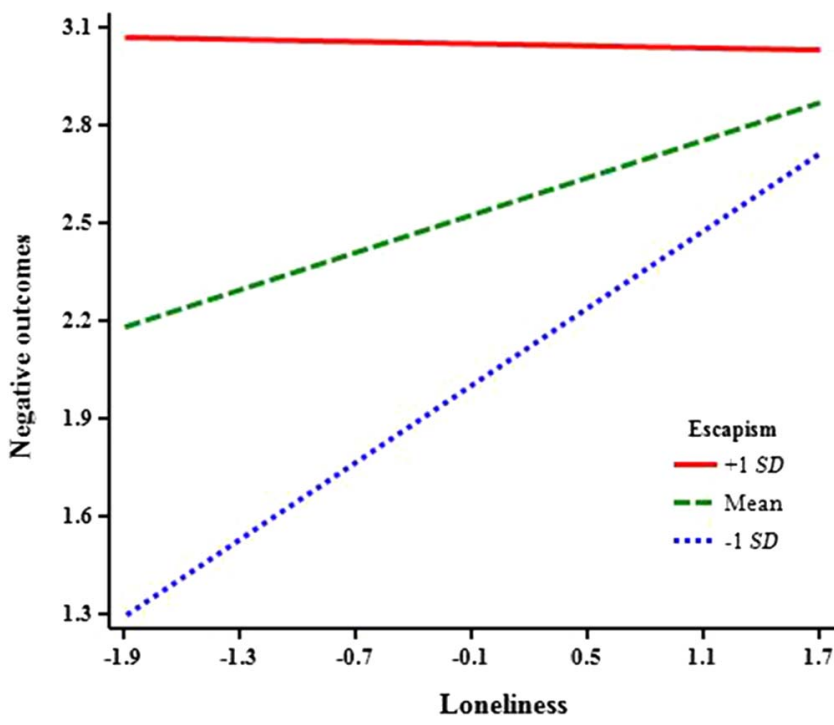

Figure 1. Escapism as a moderator of the relationship between loneliness and negative outcomes for respondents in the EOG

Table 4. Simple slope analysis of the moderating effect of escapism on the relationship between loneliness and negative outcomes

\begin{tabular}{lccc}
\hline $\begin{array}{l}\text { Level of moderating } \\
\text { variable }\end{array}$ & $+1 S D$ & $M$ & $-1 S D$ \\
\hline Intercept & 3.07 & 2.55 & 2.03 \\
$b$ & -0.01 & 0.19 & 0.40 \\
$t$ & -0.12 & $2.34^{*}$ & $3.47^{* *}$ \\
{$[95 \% \mathrm{CI}]$} & {$[-0.20,0.17]$} & {$[0.03,0.36]$} & {$[0.17,0.63]$} \\
\hline
\end{tabular}

Note. M: mean; $S D$ : standard deviation; CI: confidence interval. ${ }^{*} p<.05 .{ }^{* *} p<.01$. 
higher levels of escapism produced a higher moderating effect.

To test the interaction effects between psychosocial wellbeing and information seeking, a multiple regression model with negative outcomes as the dependent variable was fitted using the IOG (Table 5). This model explained $15.5 \%$ of the variance for the negative outcomes $\left[F_{(7,267)}=7.02\right.$, $p<.001]$. No significant interaction effect existed between loneliness and information seeking, supporting H3. However, an interaction effect was found between stress and information seeking $(b=0.41, t=2.52, p<.05)$; therefore, H4 was rejected.

A simple slope test was performed to investigate how information seeking moderated the relationship between stress and negative outcomes (Figure 2). Table 6 shows that the relationship between stress and negative outcomes was negative when levels of information seeking were low $(b=-0.47, t=-4.01, p<.001)$ and medium $(b=-0.31$, $t=-3.50, p<.001)$, but the relationship was non-significant for high levels of information seeking.

Table 5. Multiple regression model for negative outcomes with interaction terms for IOG

\begin{tabular}{lcc}
\hline & $B$ & $t$ \\
\hline Gender & 0.26 & $2.25^{*}$ \\
Age & -0.02 & -1.40 \\
Loneliness & 0.01 & 0.11 \\
Stress & -0.50 & $-3.48^{* * *}$ \\
Information seeking & 0.49 & $4.14^{* * *}$ \\
Loneliness $\times$ Information seeking & 0.19 & 1.18 \\
Stress $\times$ Information seeking & 0.41 & $2.52^{*}$ \\
$R^{2}$ & .155 & \\
\hline
\end{tabular}

Note. IOG: information-oriented group.

$* p<.05 . * * * p<.001$.

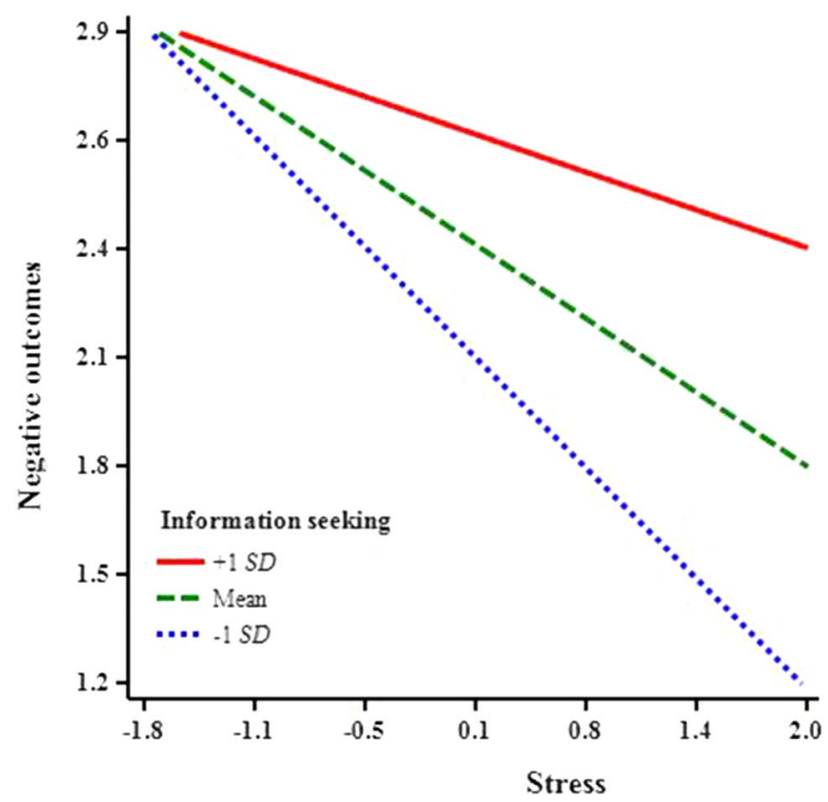

Figure 2. Information seeking as a moderator of the relationship between stress and negative outcomes for respondents in the IOG
Table 6. Simple slope analysis of the moderating effect of information seeking on the relationship between stress and negative outcomes

\begin{tabular}{lccc}
\hline $\begin{array}{l}\text { Level of } \\
\text { moderating } \\
\text { variable }\end{array}$ & & & \\
\hline Intercept & 2.68 & 2.40 & $-1 S D$ \\
$b$ & -0.16 & -0.31 & 2.13 \\
$t$ & -1.46 & $-3.50^{* * *}$ & -0.47 \\
{$[95 \% \mathrm{CI}]$} & {$[-0.37,0.06]$} & {$[-0.49,-0.14]$} & {$[-0.69,-0.24]$} \\
\hline
\end{tabular}

Note. M: mean; $S D$ : standard deviation; $\mathrm{CI}$ : confidence interval. $* * * p<.001$.

\section{DISCUSSION}

From the perspective of compensatory Internet use, research has established the moderating mechanism of escapism and psychosocial risk factors in gaming-related activities (Ballabio et al., 2017; Bowditch et al., 2018; Cheng, Sun, \& Mak, 2015; Demetrovics et al., 2011; Kardefelt-Winther, 2014a; Király et al., 2015; McNicol \& Thorsteinsson, 2017). Given the lack of evidence regarding moderation through information seeking in the literature, this study examined whether the mechanism of moderation functions differently for information-oriented motivation versus for escapismoriented motivation and psychosocial factors. Popular live game-streaming platforms such as Twitch satisfy both users' information-oriented and escapism-oriented needs, and Twitch users were thus used as the sample of this research.

Partially confirming $H 1$, this research revealed a moderating effect of escapism and loneliness. However, the moderating model is significant for individuals with low or moderate levels of escapism but non-significant for those highly motivated by escapism, as indicated through a simple slope test (Figure 1). The confirmed moderating effect of escapism and loneliness reflects the compensatory use - by individuals with felt deficiencies, such as loneliness or isolation - of the Internet or of online gaming to compensate for psychosocial problems (Kardefelt-Winther, 2014a; Valkenburg \& Peter, 2009). The partially denied result of $H 1$ (i.e., the relationship between loneliness and negative outcomes is positive when levels of escapism are high) adds an alternative perspective to debates regarding whether lonely individuals can benefit from online activities or experience a worsening of their situations. Some research has claimed the "rich get richer" and "poor get poorer" dynamic to be at play; that is, psychosocially healthy individuals tend to thrive through online activities, whereas the well-being of vulnerable individuals further diminishes (Kraut et al., 2002; Snodgrass et al., 2014). Snodgrass et al. (2018) posited that lonely individuals have more positive experiences when they are intensively involved in online video games (as opposed to playing casually). They argued that intensive involvement in games fosters a social boundary for lonely individuals and creates a sense of social inclusion and support, whereas individuals whose involvement is not so intensive experience no such benefits. By considering the effect of involvement on lonely gamers and their playing experiences, Snodgrass et al. (2018) indicated 
the partial truth of the "rich get richer" and "poor get poorer" effect. In the same vein, this study may indicate the partial truth of both effects by considering the levels of escapism in the use of live-streaming game. For those moderately or less motivated by escapism to watch live video game streaming, loneliness was both directly and indirectly (through the moderation of escapism) associated with negative gaming experiences. By contrast, for those exhibiting high levels of escapism, the association was non-significant (i.e., no poorget-poorer effect). This phenomenon might be related to the ability of lonely gamers to meaningfully interact or bond with others in the context of live-streaming games, because social interactions are known to be vital for Twitch engagement (Hilvert-Bruce, Neill, Sjoblom, \& Hamari, 2018). Therefore, a coping behavior is not absolutely adaptive or maladaptive, because levels of motivations for usage and the online context must be considered. $H 2$ was rejected because no moderating effect of escapism on the relationship between stress and negative outcomes was found. Stress is often provoked in threatening environments (Grant et al., 2003, 2014). Therefore, stress might predispose individuals to problematic Internet use without any moderating mechanism.

This study specifically examined whether information seeking moderated the relationship between the psychosocial factors and negative outcomes of watching streaming games. $H 3$ (no interaction effect between loneliness and information seeking) was supported but $H 4$ (no interaction effect between stress and information seeking) was not. A simple slope test revealed that moderate or low levels of information seeking may buffer individual susceptibilities to negative outcomes when experiencing stress. In the study of Hasan et al. (2018) on general livestreaming viewing, the motivation of information seeking was observed to be strongly associated with problematic usage patterns. On general live-streaming sites, live streamers often broadcast themselves conducting everyday tasks, such as singing, dancing, traveling, selling items, and eating food, with an emphasis on entertainment. However, viewers of game streaming may learn strategies to enhance their gaming achievements and gain stress relief.

\section{CONCLUSIONS}

This study explored the joint effects of psychosocial factors and usage motives on problematic live game-streaming viewing, which is somewhat different from game playing, although both are gaming-related activities. Despite differences between these two activities, the interaction between loneliness and escapism motivations is associated with both problematic game playing and problematic game-streaming viewing. This research also investigated the moderating effect of information seeking, which has rarely been tested in the game-related literature, and the findings indicated that the indirect effect of information seeking may buffer the effect of stress on problematic engagement in live gamestreaming viewing. The findings of this study help promote understanding regarding how individuals using similar
Internet-related coping strategies experience negative consequences differently when motivation levels and online environments are considered. In addition, the findings highlight the value of future research verifying the interplay among various use behaviors and psychosocial health that may induce or buffer negative symptoms. Furthermore, this study reconfirms a valuable methodological point, which is that objects with certain characteristics should be isolated from a sample as a whole to determine their effect on corresponding variables (Kardefelt-Winther, 2014a). For example, the IOG was separated from the EOG in this study. If this were not done, the buffering effects of information seeking would be invisible when using the whole sample.

This study has several limitations. Gaming habits were not investigated in the survey, and thus this study failed to take into consideration how participants played video games. Moreover, how individuals' social involvement in game-streaming viewing affects the relationship between motivations and outcomes remains unexplored and may be worth researching in the future. As in many other questionnaire surveys, generalizability may be limited due to the use of an online convenience sample. Finally, the causal chain or direction of effects was not ascertained due to the correlational nature of the data. Thus, future studies should use longitudinal data for further investigation.

Funding sources: None.

Authors' contribution: C-YC was the principal investigator of the research. She designed the proposal, study, and questionnaire. She was involved in data analysis and finished the manuscript. S-LC contributed to data analysis and approved the final version of the manuscript.

Conflict of interest: The authors declare no conflict of interest.

Acknowledgements: The authors are indebted to the anonymous reviewers for offering insightful suggestions.

\section{REFERENCES}

American Psychiatric Association. (2013). Diagnostic and statistical manual of mental disorders (5th ed.). Washington, DC: American Psychiatric Association.

Bae, S. M. (2017). The relationship between the type of smartphone use and smartphone dependence of Korean adolescents: National survey study. Children and Youth Services Review, 81, 207-211. doi:10.1016/j.childyouth.2017.08.012

Baggio, S., Starcevic, V., Studer, J., Simon, O., Gainsbury, S. M., Gmel, G., \& Billieux, J. (2018). Technology-mediated addictive behaviors constitute a spectrum of related yet distinct conditions: A network perspective. Psychology of Addictive Behaviors, 32(5), 564-572. doi:10.1037/adb0000379 
Ballabio, M., Griffiths, M. D., Urbán, R., Quartiroli, A., Demetrovics, Z., \& Király, O. (2017). Do gaming motives mediate between psychiatric symptoms and problematic gaming? An empirical survey study. Addictive Research \& Theory, 25(5), 397-408. doi:10.1080/16066359.2017.1305360

Blasi, M. D., Giardina, A., Giordano, C., Coco, G. L., Tosto, C., Billieux, J., \& Schimmenti, A. (2019). Problematic video game use as an emotional coping strategy: Evidence from a sample of MMORPG gamers. Journal of Behavioral Addictions, 8(1), 25-34. doi:10.1556/2006.8.2019.02

Bowditch, L., Chapman, J., \& Naweed, A. (2018). Do coping strategies moderate the relationship between escapism and negative gaming outcomes in World of Warcraft (MMORPG) players? Computers in Human Behavior, 86, 69-76. doi:10.1016/j.chb.2018.04.030

Bozoglan, B., Demirer, V., \& Sahin, I. (2013). Loneliness, selfesteem, and life satisfaction as predictors of Internet addiction: A cross sectional study among Turkish university students. Scandinavian Journal of Psychology, 54(4), 313-319. doi:10.1111/sjop.12049

Chen, C.-Y. (2013). Is the video game a cultural vehicle? Games and Culture, 8(6), 408-427. doi:10.1177/1555412013493349

Chen, C.-Y. (2018). Smartphone addiction: Psychological and social factors predict the use and abuse of a social mobile application. Information, Communication and Society. Advance online publication. doi:10.1080/1369118X.2018.1518469

Cheng, C., Sun, P., \& Mak, K. (2015). Internet addiction and psychosocial maladjustment: Avoidant coping and coping inflexibility as psychological mechanisms. Cyberpsychology, Behavior, and Social Networking, 18(9), 539-546. doi:10.1089/cyber.2015.0121

Codeahoy. (2017). Cluster analysis using K-means explained. Retrieved from https://codeahoy.com/2017/02/19/cluster-analysis-using-k-means-explained/

Deleuze, J., Maurage, P., Schimmenti, A., Nuyens, F., Melzer, A., \& Billieux, J. (2019). Escaping reality through videogames is linked to an implicit preference for virtual over real-life stimuli. Journal of Affective Disorders, 245, 1024-1031. doi:10.1016/j. jad.2018.11.078

Demetrovics, Z., Urbán, R., Nagygyörgy, K., Farkas, J., Zilahy, D., Mervó, B., Reindl, A., Ágoston, C., Kertész, A., \& Harmath, E. (2011). Why do you play? The development of the Motives for Online Gaming Questionnaire (MOGQ). Behavior Research Methods, 43(3), 814-825. doi:10.3758/s13428-011-0091-y

Ehrenberg, A., Juckes, S., White, K. M., \& Walsh, S. P. (2008). Personality and self-esteem as predictors of young people's technology use. Cyberpsychology, Behavior, and Social Networking, 11(6), 739-741. doi:10.1089/cpb.2008.0030

Fioravanti, G., Dettore, D., \& Casale, S. (2012). Adolescent Internet addiction: Testing the association between self-esteem, the perception of Internet attributes, and preference for online social interactions. Cyberpsychology, Behavior, and Social Networking, 15(6), 318-323. doi:10.1089/cyber.2011.0358

Forest, J. (2017). When do you need to standardize the variables in a regression model? Retrieved from http://statisticsbyjim.com/ regression/standardize-variables-regression/

Fortune. (2018). Facebook debuts new service to capitalize on growth in video games as a spectator sport. Retrieved from http://fortune. com/2018/06/08/facebook-game-streaming-platform/

Grant, K. E., Compas, B. E., Stuhlmacher, A. F., Thurm, A. E., McMahon, S. D., \& Halpert, J. A. (2003). Stressors and child and adolescent psychopathology: Moving from markers to mechanisms of risk. Psychological Bulletin, 129(3), 447-466. doi:10.1037/0033-2909.129.3.447

Grant, K. E., McMahon, S. D., Carter, J. S., Carleton, R. A., Adam, E. K., \& Chen, E. (2014). The influence of stressors on the development of psychopathology. In M. Lewis \& K. D. Rudolph (Eds.), Handbook of developmental psychopathology (3rd ed., pp. 205-223). New York, NY: Springer.

Guo, Y., You, X., Gu, Y., Wu, G., \& Xu, C. (2018). A moderated mediation model of the relationship between quality of social relationships and Internet addiction: Mediation by loneliness and moderation by dispositional optimism. Current Psychology. Advance online publication. 1-11. doi:10.1007/s12144018-9829-3

Hagström, D., \& Kaldo, V. (2014). Escapism among players of MMORPGs-conceptual clarification, its relation to mental health factors, and development of a new measure. Cyberpsychology, Behavior, and Social Networking, 17(1), 19-25. doi:10.1089/cyber.2012.0222

Hasan, M. R., Jha, A. K., \& Liu, Y. (2018). Excessive use of online video streaming services: Impact of recommender system use, psychological factors, and motives. Computers in Human Behaviour, 80, 220-228. doi:10.1016/j.chb. 2017.11.020

Hollett, K. B., \& Harris, N. (2019). Dimensions of emotion dysregulation associated with problem video gaming. Addiction Research \& Theory. Advance online publication. 1-8. doi:10.1080/16066359.2019.1579801

Hilvert-Bruce, Z, Neill, J. T., Sjoblom, M., \& Hamari, J. (2018). Social motivations of live-streaming viewer engagement on Twitch. Computers in Human Behavior, 84, 58-67. doi:10.1016/j.chb.2018.02.013

Hinkley, T., Timperio, A., Salmon, J., \& Hesketh, K. (2017). Does preschool physical activity and electronic media use predict later social and emotional skills at 6 to 8 years? A cohort study. Journal of Physical Activity and Health, 14(4), 308-316. doi:10.1123/jpah.2015-0700

Howell, D. C. (2012). Statistical methods for psychology. Belmont, CA: Wadsworth.

Kardefelt-Winther, D. (2014a). The moderating role of psychosocial well-being on the relationship between escapism and excessive online gaming. Computers in Human Behavior, 38, 68-74. doi:10.1016/j.chb.2014.05.020

Kardefelt-Winther, D. (2014b). A conceptual and methodological critique of Internet addiction research: Towards a model of compensatory Internet use. Computers in Human Behavior, 31, 351-354. doi:10.1016/j.chb.2013.10.059

Kardefelt-Winther, D. (2017). Conceptualizing Internet use disorders: Addiction or coping process? Psychiatry and Clinical Neurosciences, 71(7), 459-466. doi:10.1111/ pcn. 12413

Kim, J., LaRose, R., \& Peng, W. (2009). Loneliness as the cause and the effect of problematic Internet use: The relationship between Internet use and psychological well-being. Cyberpsychology, Behavior, and Social Networking, 12(4), 451-455. doi:10.1089/cpb.2008.0327

Király, O., Urbán, R., Griffiths, M. D., Ágoston, C., Nagygyörgy, K., Kökönyei, G., \& Demetrovics, Z. (2015). The mediating effect of gaming motivation between psychiatric symptoms and problematic online gaming: An online survey. Journal of Medical Internet Research, 17(4), e88. doi:10.2196/jmir.3515 
Klobas, J. E., McGill, T. J., Moghavvemi, S., \& Paramanathan, T. (2018). Compulsive YouTube usage: A comparison of use motivation and personality effects. Computers in Human Behavior, 87, 129-139. doi:10.1016/j.chb.2018.05.038

Kraut, R., Kiesler, S., Boneva, B., Cummings, J., Helgeson, V., \& Crawford, A. (2002). Internet paradox revisited. Journal of Social Issues, 58(1), 49-74. doi:10.1111/1540-4560.00248

Kuss, D. J., Griffiths, M. D., \& Pontes, H. M. (2017). Chaos and confusion in DSM-5 diagnosis of Internet gaming disorder: Issues, concerns, and recommendations for clarity in the field. Journal of Behavioral Addictions, 6(2), 103-109. doi:10.1556/ 2006.5.2016.062

Kuss, D., Louws, J., \& Wiers, R. (2012). Online gaming addiction? Motives predict addictive play behavior in massively multiplayer online role-playing games. Cyberpsychology, Behavior, and Social Networking, 15(9), 480-485. doi:10.1089/ cyber.2012.0034

Kuo, A., Lutz, R. J., \& Hiler, J. L. (2016). Brave new World of Warcraft: A conceptual framework for active escapism. Journal of Consumer Marketing, 33(7), 498-506. doi:10.1108/ JCM-04-2016-1775

Laconi, S., Pirès, S., \& Chabrol, H. (2017). Internet gaming disorder, motives, game genres and psychopathology. Computers in Human Behavior, 75, 652-659. doi:10.1016/j. chb.2017.06.012

Lahti, M. (2003). As we become machines: Corporealized pleasures in video games. In M. Wolf \& B. Perron (Eds.), The video game theory reader (pp. 157-170). New York, NY: Routledge.

Maroney, N., Williams, B. J., Thomas, A., Skues, J., \& Moulding, R. (2018). A stress-coping model of problem online video game use. International Journal of Mental Health and Addiction. Advance online publication. 1-14. doi:10.1007/s11469-018-9887-7

McNicol, M. L., \& Thorsteinsson, E. B. (2017). Internet addiction, psychological distress, and coping responses among adolescents and adults. Cyberpsychology, Behavior, and Social Networking, 20(5), 296-304. doi:10.1089/cyber. 2016.0669

Ostovar, S., Allahyar, N., Aminpoor, H., Moafian, F., Nor, M. B. M., \& Griffiths, M. D. (2016). Internet addiction and its psychosocial risks (depression, anxiety, stress and loneliness) among Iranian adolescents and young adults: A structural equation model in a cross-sectional study. International Journal of Mental Health and Addiction, 14(3), 257-267. doi:10.1007/s11469-015-9628-0

Parker, B. J., \& Plank, R. E. (2000). A uses and gratifications perspective on the Internet as a new information source. American Business Review, 18(2), 43-49. Retrieved from https:// search-proquest-com.ezproxy.lib.asia.edu.tw:2443/docview/216 306467? accountid $=8395$

Payne, K., Keith, M. J., Schuetzler, R. M., \& Giboney, J. S. (2017). Examining the learning effects of live streaming video game instruction over Twitch. Computers in Human Behavior, 77, 95-109, doi:10.1016/j.chb.2017.08.029.

Petry, N. M., Rehbein, F., Gentile, D. A., Lemmens, J. S., Rumpf, H. J., Mößle, T., Bischof, G., Tao, R., Fung, D. S., Borges, G., Auriacombe, M., González Ibánez, A., Tam, P., \& Õ'Brien, C. P. (2014). An international consensus for assessing Internet gaming disorder using the new DSM-5 approach. Addiction, 109(9), 1399-1406. doi:10.1111/add.12457

Pittman, M., \& Reich, B. (2016). Social media and loneliness: Why an Instagram picture may be worth more than a thousand
Twitter words. Computers in Human Behavior, 62, 155-167. doi:10.1016/j.chb.2016.03.084

Pontes, H. M., \& Griffiths, M. D. (2016). Portuguese validation of the Internet Gaming Disorder Scale-Short-Form. Cyberpsychology, Behavior, and Social Networking, 19(4), 288-293. doi:10.1089/cyber.2015.0605

Rumpf, H. J., Achab, S., Billieux, J., Bowden-Jones, H., Carragher, N., Demetrovics, Z., Higuchi, S., King, D. L., Mann, K., Potenza, M., Saunders, J. B., Abbott, M., Ambekar, A., Aricak, O. T., Assanangkornchai, S., Bahar, N., Borges, G., Brand, M., Chan, E. M., Chung, T., Derevensky, J., Kashef, A. E., Farrell, M., Fineberg, N. A., Gandin, C., Gentile, D. A., Griffiths, M. D., Goudriaan, A. E., Grall-Bronnec, M., Hao, W., Hodgins, D. C., Ip, P., Király, O., Lee, H. K., Kuss, D., Lemmens, J. S., Long, J., Lopez-Fernandez, O., Mihara, S., Petry, N. M., Pontes, H. M., Rahimi-Movaghar, A., Rehbein, F., Rehm, J., Scafato, E., Sharma, M., Spritzer, D., Stein, D. J., Tam, P., Weinstein, A., Wittchen, H. U., Wölfling, K., Zullino, D., \& Poznyak, V. (2018). Including gaming disorder in the ICD-11: The need to do so from a clinical and public health perspective. Journal of Behavioral Addictions, 7(3), 556-561. doi:10.1556/2006.7.2018.59

Shen, C., \& Williams, D. (2011). Unpacking time online: Connecting Internet and massively multiplayer online game use with psychosocial well-being. Communication Research, 38, 124-149. doi:10.1177/0093650210377196

Smith, C. (2018). 52 amazing Twitch stats and facts. Retrieved from https://expandedramblings.com/index.php/twitch-stats/

Snodgrass, J. G., Bagwell, A., Patry, J. M., Dengah, H. F., II, Smarr-Foster, C., Van Oostenburg, M., \& Lacy, M. G. (2018). The partial truths of compensatory and poor-get-poorer Internet use theories: More highly involved videogame players experience greater psychosocial benefits. Computers in Human Behavior, 78, 10-25. doi:10.1016/j.chb.2017.09.020

Snodgrass, J. G., Lacy, M. G., Dengah, H. J., II, Eisenhauer, S., Batchelder, G., \& Cookson, R. J. (2014). A vacation from your mind: Problematic online gaming is a stress response. Computers in Human Behavior, 38, 248-260. doi:10.1016/j.chb.2014.06.004

Song, I., Larose, R., Eastin, M. S., \& Lin, C. A. (2004). Internet gratifications and Internet addiction: On the uses and abuses of new media. CyberPsychology \& Behavior, 7(4), 384-394. doi:10.1089/cpb.2004.7.384

Soper, D. S. (n.d.). Interaction. Retrieved from https://www. danielsoper.com/interaction/default.aspx

Sung, Y. H., Kang, E. Y., \& Lee, W.-N. (2018). Why do we indulge? Exploring motivations for binge watching. Journal of Broadcasting \& Electronic Media, 62(3), 408-426. doi:10.1080/08838151.2018.1451851

Valkenburg, P. M., \& Peter, J. (2009). Social consequences of the Internet for adolescents a decade of research. Current Directions in Psychological Science, 18(1), 1-5. doi:10.1111/j.14678721.2009.01595.x

van Rooij, A. J., Ferguson, C. J., Colder Carras, M., KardefeltWinther, D., Shi, J., Aarseth, E., Bean, A. M., Bergmark, K. H., Brus, A., Coulson, M., Deleuze, J., Dullur, P., Dunkels, E., Edman, J., Elson, M., Etchells, P. J., Fiskaali, A., Granic, I., Jansz, J., Karlsen, F., Kaye, L. K., Kirsh, B., Lieberoth, A., Markey, P., Mills, K. L., Nielsen, R. K. L., Orben, A., Poulsen, A., Prause, N., Prax, P., Quandt, T., Schimmenti, A., Starcevic, V., Stutman, G., Turner, N. E., van Looy, J., \& Przybylski, A. K. (2018). A weak scientific basis for gaming disorder: Let 
us err on the side of caution. Journal of Behavioral Addiction, 7(1), 1-9. doi:10.1556/2006.7.2018.19

Warttig, S. L., Forshaw, M. J., South, J., \& White, A. K. (2013). New, normative, English-sample data for the Short Form Perceived Stress Scale (PSS-4). Journal of Health Psychology, 18(12), 1617-1628. doi:10.1177/1359105313 508346

WHO. (2018). Gaming disorder. Retrieved from https://www. who.int/features/qa/gaming-disorder/en/

Yee, N. (2007). Motivations for play in online games. CyberPsychology \& Behavior, 9(6), 772-775. doi:10.1089/cpb.2006. 9.772
Young, K. (1998). Internet addiction: The emergence of a new clinical disorder. CyberPsychology \& Behavior, 1(3), 237-244. doi:10.1089/cpb.1998.1.237

Young, K. (2009). Internet addiction. American Behavioral Scientist, 4, 402-415. doi:10.1177/0002764204270278

Zanetta, D. F., Zermatten, A., Billieux, J, Thorens, G., Bondolfi, G., Zullino, D., \& Khazaal, Y. (2011). Motivations to play specifically predict excessive involvement in massively multiplayer online role-playing games: Evidence from an online survey. European Addiction Research, 17(4), 185-189. doi:10.1159/000326070 
APPENDIX: KEY MEASUREMENT OF THE SURVEY

\section{LONELINESS}

I often feel like I lack companionship

I often feel like I am left out of social situations

I often feel like I am isolated from others

\section{STRESS}

I often feel that I am unable to control the important things in my life

I often feel unconfident about my ability to handle personal problems

I often feel that things are going my way

I often feel difficulties are piling up so high that I cannot overcome

\section{MOTIVATION-ESCAPISM}

I watch streaming games in order to escape from reality I watch streaming games in order to forget about troubles

I watch streaming games in order to avoid bad feelings

\section{MOTIVATION-INFORMATION SEEKING}

I watch streaming games in order to get new ideas about gaming

I watch streaming games in order to learn things that I need to know about games

I watch streaming games in order to improve my accomplishment in the games

I watch streaming games in order to know what is going with the video games

\section{NEGATIVE OUTCOMES}

I often lose sleep because of the time I spend on game streaming viewing

I often skip meals or delay my eating because I am busy for game streaming viewing

I have had conflicts with my partner or parents over the time I spend on game streaming viewing

I have lost contact with some friends because I'd rather spend time on game streaming viewing

My school/job performance has suffered because of the time I spend on game streaming viewing 